\title{
The Research and Development of Sanya Big Tourism Performing Arts Culture Brand Based on the Romantic Show of Sanya
}

\author{
Wen Zhou ${ }^{1,2, a}$, Xuebin Huang ${ }^{1, b}$, Jia Zhu ${ }^{3, c^{*}}$ and Kun Zhang ${ }^{1, d}$ \\ Education Center of MTA, Hainan Tropical Ocean University, Sanya, Hainan, 572022, China \\ Department of Tourism Management, Zhangjiajie Institute of Aeronautical Engineering, Zhangjiajie, \\ Hunan, 427000, China \\ College of Art and Creativity, Hainan Tropical Ocean University, Sanya, Hainan 572022, China

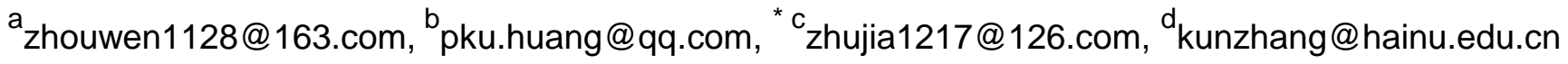 \\ *The corresponding author
}

Keywords: International tourism island; Tourism and performance; Tourism economics; The Romantic Show

\begin{abstract}
This paper is going to carried out based on the policies of an international tourism island, Hainan to study on The Romantic Show of Sanya based on its real tourism situation. In addition, it will also study on the big brand in terms of Sanya tourism performance from the perspectives of development history so as to summarize successful experience, expecting to provide reference for the construction mode of Sanya's tourism.
\end{abstract}

\section{Introduction}

The Romantic Show mode is a brand created by Worldland in terms of tourism and culture and it has created ten tourism areas and thirty theme parks including Hangzhou Songcheng Tourism Area, Sanya Songcheng Tourism Area, Lijiang Songcheng Tourism Area, Jiuzhai Songcheng Tourism Area etc as well as fifty tourism performance shows including The Romantic Show of Songcheng, The Romantic Show of Lijiang, The Romantic Show of Jiuzhai, giant flames and cross flash etc. In addition, there are also the biggest hotel in the world, Yunman hotel, The Romantic Show hotel with thousands of rooms. Furthermore, several cultural programs are created to establish a big brand and franchises all over the nation.

\section{A Brief Introduction of the Romantic Show of Sanya Construction}

Sanya Songcheng cultural resort area is located in Yingbin avenue of Sanya's downtown area with a total invest 10 billion RMB. Inside of the resort area, there are Songcheng The Romantic Show of Sanya area, Songcheng water park, Songcheng ice world, Songcheng sea park, Songcheng lanpingguo park, Sanya Yunman hotel and Songcheng biggest mansion. So, the resort area includes theme park, cultural performance art, recreation and hotels, which is a paradise place for people. Since its opening on September 25 2013, The Romantic Show of Sanya area has received around 50,000 people and is widely acclaimed. At the beginning, The Romantic Show of Sanya show was on stage per day, but now it has two shows per day. During the golden week of spring this year, there are three shows per day with full capacity. Since its opening for 7 months, the operating revenue has already achieved 100,000,000 RMB and every acre's income is over than a million RMB. This outcome has encouraged enterprise and government and also made people confident about the following construction. The Romantic Show of Sanya, as the first duplication of Songcheng successfully continued the work: in 2014, the number of 
tourism was over millions since the opening for around 7 months and the avenue is around one hundred million. Every day, there are two cultural performances with full capacity and applaud. The Romantic Show of Sanya deeply combined culture and tourism, successfully realized a win-win strategy in terms of economic efficiency as well as social efficiency, which did not only facilitate the development of the tourism chain but also helped local citizens and tourism have a clear understanding of Sanya. Based on it, the local culture is protected and will be inherited for a long time and the success of this tourism performance brand as well as its operation mechanism has become a typical case of Sanya and Hainan as a whole. Therefore, the study on the big brand in terms of tourism performance is of typical importance of Sanya and Hainan's tourism development.

In some tourists' mind, The Romantic Show of Sanya is just an on stage show. In reality, The Romantic Show of Sanya project is a commercial mode based on park and cultural performance, which creates Elephant Valley, Mingren Mountain, Ghost Panic and Folk Acrobat Skills and combines culture as well as tourism so as to realize a deep combination. The designs of The Romantic Show resort area, for example, Turn round Deer, Lady Xian Legend, Jianzhen Crosses the Ocean to Japan are all famous historical events with deep culture. These events along with dance, singing, acrobatics, sound, light and electricity as well as market promotion, will bring about wonderful performance.

In 2015, The Romantic Show of Sanya Tourism Performance Co.,Ltd. won top 10 excellent cultural enterprises prize of Sanya. The Romantic Show of Sanya Tourism Performance Co.,Ltd. is a subsidiary of Songcheng Performance Co.,Ltd. and Sanya Songcheng tourism spot is the first project created by Worldland, which focuses on the history and culture of Sanya with a combination of cultural performance. This tourism spot is listed as a key cultural project of Hainan and it began to establish The Romantic Show of Sanya tourism spot, Ice World, colorful animal zoo and Langlanglangshui park etc.

\section{The Development Mode of the Romantic Show of Sanya}

Based on Tourism Spot Location and Market Research. When the tourism market of Sanya is becoming riper, the demand of both domestic and foreign tourists is becoming diversified so natural resource development is not enough. Therefore, we have to dig deep into the unique and regional culture of Sanya to demonstrate new resources and leave a deep impression on tourists. The Romantic Show of Sanya is another The Romantic Show project Songyan Performance Co.,Ltd established other than Hangzhou, which is going to seek for the heritage of Hainan culture as well as Sanya culture. After it was done, it also requested lots of suggestions from various perspectives with continue adjustment to perfect it.

Based on Tourism Spot Operation. The Romantic Show of Sanya tourism spot is definitely the best one Sanya has introduced these two years, which closely tied culture and tourism together with a clear market target and good feedback among tourists. It highlighted the night tour and before it, there are various tourism performance shows such as The crown of Sanya, Haitang Bay show etc. The emergence of The Romantic Show of Sanya does not only enrich the night tour resources but also acts as the leading role and brings about different features to improve the quality of it.

There are over 10,000,000 people spending a night in Sanya and it is an internationally renowned sea front city. The Romantic Show of Sanya project is located in the downtown area with regionally unique features, which can fill the gap of night tour as well as the lack of tourism package.

Based on the Tourism Choice. The Romantic Show of Sanya chose the night tour from the perspective of competitive differentiation; Judging from night tour, The Romantic Show of Sanya hold high the banner of the local culture of Hainan and Sanya, which has created a new way to integrate culture and tourism. Therefore, it realized competitive differentiation with big success. 


\section{Study on the Tourism Performance Brand Construction}

Unique Cultural Brand. The deep development of regional culture plays a pivotal role in the success of tourism performance. Based on deep digging and refinement of regional culture as well as cultural elements, we established unique cultural brands, which are beneficial to let tourists experience cultural difference and provide qualified products.

Create Brand Based on Creation Innovation. Creation or innovation can be considered as important methods to improve the core competition of tourism performance products and creative cultural digging can demonstrate a fresh feeling. It cannot only be conducive to explain the product taste as well as the cultural connotation and the charm of art but also become a new highlight of brand construction. Only when tourism performance products establish a creative outline, combine good planning philosophy can they create unique tourism performance products and establish totally new tourism performance brand and win the recognition among customers so as to be adapted to the market.

\section{Government should Support Brand}

The big support of local government is powerful guarantee for the health and sound development of tourism performance products, which include the following aspects: in terms of policy, the government should effectively guide excellent tourism performance products and the same time, make preferential and supportive policies in terms of land, loan, tax and labor so as to provide the investment and finance with a good market environment; in terms of capital, the government should take advantage of the administration function to positively promote guide and supervise the product finance so as to provide capital guarantee for the brand construction as well as the following up development; in terms of promotion, local government should vigorously promote to both domestic and foreign media and approve its fame so as to create a brand effect.

Brand Promotion. To improve the promotion strength of tourism performance products will inevitably create a good effect. To begin with, we have to innovate the tickets selling methods and expand marketing channels so as to establish a ticket selling channel which can keep in line with international development; secondly, we have to further perfect the tourism performance chain and establish tickets companies so as to change the single selling means fundamentally; more over, we should also carry out enough market research so as to properly determine the price; finally, we should also adopt effective promotion strategies so as to successfully sell the brand.

Continually Update Brand. If you want to create a eternal brand, we cannot be separated from innovation because only continuous innovation will keep people having fresh experience with ever-lasting interest. By digging deep into the connotation, constantly updating the program contents, create new things, can we bring our customers with diversified experience. Based on this, can we strengthen the attraction and create a ever-lasting brand effect to finally win the market share and create the sustainable development of products.

\section{Summary}

By studying on the successful case of The Romantic Show program all over the nation as well as the successful tourism performance products implementation in Sanya, we will research the new development trend of modern tourism, the new connotation of tourism spots, as well as the methods to promote regional economy, establish brand effect bring about references for other cities to create a famous brand. The success of The Romantic Show of Sanya as well as its tourism performance products should be referred to Sanya, Hainan and the whole nation as a whole. By referring to its experience, can we create tourism performance culture, brand and a new tourism management mode in the new era. 


\section{Acknowledgement}

This research was financially supported by the Hainan Province Tourism Management Key Disciplines Construction Project; the MTA Teaching Reform Research Project (No.MTAJG2016-07); the Research Project of Educational Reform in Higher Education in Hainan Province (No.Hnjg2015ZD-13); the Scientific and Technological Cooperative Project for College and Region of Sanya (No.2014YD36); the Sanya Planning Projects of Philosophy and Social Sciences (No.SYSK2017-03); the 2016 Hainan Education Science Study Topics of the "13th Five-Year " Plan (No.QJY13516030).

\section{References}

[1] Z.Y. Chen: Take the Advantages of Regional Resources into Play Create Famous Cultural Tourism City, Study Monthly, (2010) No.2, p. 70.

[2] G.C. Qu, X.Z. He, Y. Zhao: Brief Analysis of the Development and Utilization of Tourism Resources Related to Li Bai Culture in Maanshan, Journal of Anhui University of Technology(Social Sciences), Vol. 29 (2009) No.1, p. 34-35+51.

[3] L.W. Zhao: On the Current Situation and Countermeasure of Domestic Tourism Performing Products, Journal of Sichuan Vocational and Technical College, Vol. 21 (2011) No.1, p. 123-124.

[4] S.M. Fang, J. Yang: An Overall Summary on Domestic Tourism Performance, Tourism Forum, Vol. 4 (2011) No.4, p. 152-157.

[5] Q. Zhang: Operational Mode and Experiences of Tourism Performance in Hangzhou-A Case Study of Thousands of Years of Love for Songcheng and Impressive West Lake, Journal of Qingdao Hotel Management College, Vol. 4 (2009) No.4, p. 24-28.

[6] K.H. Wang: Study on the Current Condition and Development Trend of Domestic Tourism Performance, Business Economy, (2010) No.3, p. 102-103.

[7] J.N. Hou, H.H. Yang, X.D. Li: Thought on the Regional Cultural Elements of Tourism Performance Products- Take Image_Liusanjie as an Example, Tourism Forum, (2010) No.3, p. 284-287.

[8] J. Zhu: Study on the Music Culture Inheritance and Development of the Minorities Living on the Side of Qiongtai, The Border Economy and Culture, (2014) No.1, p. 166-167. 